\title{
Phage and Host Genetic Determinants of the Specific Anticodon Loop Cleavages in Bacteriophage T4-infected Escherichia coli CTr5X
}

\author{
Gabriel Kaufmann ${ }^{1,2}$, Michael David ${ }^{1} \uparrow$, Gian Domenico Borasio ${ }^{1}$ \\ Ariella Teichmann ${ }^{1}$, Arnon Paz ${ }^{2}$, Michal Amitsur ${ }^{2}$
}

\author{
${ }^{1}$ Biochemistry Department \\ Weizmann Institute of Science \\ Rehovot, Israel 76100 \\ ${ }^{2}$ Biochemistry Department \\ Tel Aviv University \\ Ramat Aviv, Israel 69978
}

\author{
Robert Green and Larry Snyder \\ Department of Microbiology \\ Michigan State University \\ East Lansing, MI 48824-1011, U.S.A.
}

(Received 25 October 1984, and in revised form 13 September 1985)

\begin{abstract}
Anticodon loop cleavages of two host tRNA species occur in bacteriophage T4-infected Escherichia coli CTr5X, a host strain restricting phage mutants deficient in polynucleotide kinase $(p n k)$ or RNA ligase $(r l i)$. The cleavage products accumulate with the mutants but are further processed in wt infection through polynucleotide kinase and RNA ligase reactions. Inactivating mutations in $s i p$ suppress $p n k^{-}$or $r l i^{-}$mutations in $E$. coli CTr5X and, as shown here, also abolish the anticodon nuclease, implicating the stp product with this activity. We show also that there exist other suppressing mutations of a $m^{-} k^{-}\left(p s e T_{2}\right)$ mutation that appear not to affect the anticodon nuclease and are not in stp. It has been shown that a single locus in $E$. coli CTr5X, termed prr, determines the restriction of $p n k^{-}$ or $r l i{ }^{-}$mutants. A transductant carrying prr featured upon infection the anticodon nuelease reaction products, suggesting that prr determines the specific manifestation of this activity. However, prr does not encode the tRNA species that are vulnerable to the anticodon nuclease.
\end{abstract}

\section{Introduction}

Polynucleotide kinase (Richardson, 1965) and RNA ligase (Silber et al., 1972) have been investigated thoroughly in vitro and were applied in many synthetic and analytical reactions (Kleppe \& Lillehaug, 1977; Higgins \& Cozzarelli, 1979; Uhlenbeck \& Gumport, 1982) but their physiological roles are not well-understood (cf. Snyder, 1983). Polynucleotide kinase catalyzes $\gamma$-phosphoryl transfer from ATP to 5'-OH polynucleotide termini. The protein also harbors a $3^{\prime}$-phosphatase function. The locus encoding these functions is termed interchangeably $p s e^{\prime} T^{\prime}$ or $p n k$ (Becker \& Hurwitz,

+ Present address: Biology Department, Massachusetts Institute of Technology, Cambridge, MA 02139, U.S.A.
1967; Depew \& Cozzarelli, 1974; Cameron \& Chlenbeck, 1977; Sirotkin et al., 1978) but we shall refer to polynucleotide kinase deficient mutants as $p n k^{-}$for convenience.

RNA ligase catalyzes phosphodiester bond formation between $3^{\prime}-\mathrm{OH}$ (acceptor) and $5^{\prime}-\mathrm{P}$ (donor) termini of polynucleotides, single-stranded ribonucleotide acceptors being preferred (Uhlenbeck \& Gumport, 1982). RNA ligase is the product of gene 63 (Snopek et al., 1977), which also encodes a tail fiber attachment activity (TFA, Wood \& Henninger, 1969). Despite their coresidence, RNA ligase and TFA are unrelated in their requirements (Snopek et al., 1977) and can be differentiated by distinct mutations (Runnels et al., 1982). We shall refer to RNA ligase deficient mutants as $\mathrm{rli}^{-}$.

It has been suggested that polynucleotide kinase 
and RNA ligase participate in host tRNA cleavage and reunion (Kaufmann \& Kallenbach, 1975; David et al., 1979). This hypothesis was essentially confirmed by following the fate of host tRNA during phage infection of Escherichia coli CTr5X (David et al., 1982a,b; Kaufmann \& Amitsur, 1985). This strain is restrictive to $p s e T^{-}$(Depew \& Cozzarelli, 1974), pnk (Sirotkin et al., 1978) or $\mathrm{rli}^{-}$ mutants (Runnels et al., 1982). A bacteriophage T4induced nuclease that cleaves two tRNA species $3^{\prime}$ to the anticodon is specifically manifested in infected $E$. coli CTr5X but not in other host strains that are permissive to $\mathrm{pnk}^{-}$or $\mathrm{rli}^{-}$mutants (David et al., 1982a). The CTr5X-specific cleavages are additional to the cleavage of the host leucine tRNA $_{1}$, which occurs also in the permissive strains (Kano-Sueoka \& Sueoka, 1968; Yudelevich, 1971; David et al., 1982a) and depends on a different T4 protein (David et al., 1982a). Both leucine tRNA and the CTr5X-specific tRNA fragments disappear in the course of wild-type infection but only the latter accumulate with $\mathrm{pnk}^{-}$and $\mathrm{rli}^{-}$mutants, suggesting that the products generated by the anticodon nuclease are normally processed by polynucleotide kinase and $\mathrm{RNA}$ ligase through terminal phosphoryl group rearrangement followed by religation (David et al.. 1982b). Indeed, a tRNA species corresponding to the ligation product of the CTr5X-specific fragments in vitro is found in uninfected $E$. coli CTr5X as well as late in $w t$ infection but is depleted in $\mathrm{rl}^{-}$infection. Apparently, this tRNA species is first eleaved and then religated, without undergoing a net change (Kaufmann \& Amitsur, 1985).

Inactivating mutations in another T4 gene $(s t p)$ allow the growth of $p s e T^{-}\left(p n k^{-}\right)$and $\mathrm{rli}^{-}$mutants in E. coli CTr5X (Depew \& Cozzarelli, 1974; Runnels et al., 1982). We report here that $s t p^{-}$ mutants do not generate the anticodon nuclease reaction products, indicating that stp encodes a protein needed for the nuclease activity. In addition, we describe here another suppressor of at least one $p s e T$ mutation that is distinct from $s t p$

The E. coli CTr5X locus that restricts T4 pnk and $\mathrm{rli}^{-}$mutants (prr) was previously mapped in the E. coli CTr5X chromosome (Abdul-Jabbar \& Snyder, 1984). We show here that prr determines the specific manifestation of the anticodon nuclease activity upon $\mathrm{T} 4$ infection but does not encode the cleaved tRNA.

\section{Materials and Methods}

\section{(a) Strains}

The phage mutants in 3'-phosphatase and polynucleotide kinase. pseT2 and pseT $\Delta 1$. were isolated by Depew \& Cozzarelli (1974) and Sirotkin ef al. (1978). respectively. The RNA ligase mutant $r l i-13$ was isolated by Runnels et al. (1982). Spontaneous revertants of pse $T$ and $r l i$ mutants were isolated by plating the parent strains on E. coli CTr5X according to Depew \& Cozzarelli (1974). Sa^3 and other stp deletion mutants were described by Depew ef al. (1975). The bacterial strain E. coli CTr5X was constructed by Depew \& Cozzarelli (1974) by crossing an $E$. coli K-12 strain with the clinical isolate CT196. E. coli B834 was isolated by Wood (1966). The isolation of a phage Pl transductant of E. coli B834 that is termed BJMnlo and carries the prr (poly. nucleotide kinase. RNA ligase restricting) locus of $E$. coli CTr5X and a nearby tet gene. as well as the isolation of Tets deletion mutants of $E$. coli BJMn10 without (BJMnI1) or with (BJMnl2) the prr function. were described by Abdul-Jabbar \& Snyder (1984). Table I summarizes the relevant properties of these strains.

(b) Determination of anticoton nuclease actirity in vivo

Host tRNA was pulse-labeled in cico. extracted at various times of $\mathrm{T} 4$ infection. and analyzed according to

Table 1

Bacteriophage and bacterial strains

\begin{tabular}{|c|c|c|}
\hline $\begin{array}{l}\text { Strains, phage } \\
\text { or bacteria }\end{array}$ & Relevant properties & Reference or source \\
\hline \multicolumn{3}{|c|}{ A. Tt phage strains } \\
\hline$s a \Delta 3$ & Deletion spanning $s t p$ and $a c$ & Depew of al. (1975) \\
\hline pseTul & Deletion including $p s e T$ & Snyder et al. (1976) \\
\hline pse $T 2$ & Point mutant in pse $T$ & Depew \& Cozzarelli $(1974)$ \\
\hline rli-13 & Point mutant in $r l i$ & Runnels of al. (1982) \\
\hline \multicolumn{3}{|c|}{ pse $T 2$ revertants: } \\
\hline Ra & Apparent Pnk ${ }^{+}$ & This study \\
\hline $\mathrm{Rb}$ & $p s e T 2, s t p^{-}$ & This study \\
\hline Re & $\begin{array}{l}p s e T 2, \text { mutated in a novel suppressor, } \\
\text { distinct from stp and } p s e T\end{array}$ & Thus study \\
\hline \multicolumn{3}{|c|}{ B. E. coli strains } \\
\hline$(\mathrm{Tr} 5 \mathrm{X}$ & $\begin{array}{l}\text { Hybrid K-12 } \mathrm{CT} \text { (96, restrictive to } p s e T^{-} \\
\text {or } r i^{-} \text {phage }\left(p r r^{r}\right)\end{array}$ & Depew \& ('ozzarelli (1974) \\
\hline B831 & E. coli $\mathbf{B}$ met ${ }^{-} r_{\mathrm{B}}^{-} m_{\mathrm{B}}^{-}$ & Wood $(1966)$ \\
\hline B.JMnlo & $\begin{array}{l}\mathrm{Te}^{r}, p r r^{r} \text { transductant from the cross } \\
\text { CTr5X } \times \text { B834 }\end{array}$ & Abdul-Jabbar \& Snyder (1984) \\
\hline B.JMnII & $\begin{array}{l}\mathrm{Te}^{s}, p_{r} r^{p} \text { deletion mutant derived from } \\
\text { BJMn } 10\end{array}$ & Abdul-Jabbar \& Snyder (1984) \\
\hline $\mathrm{B} . \mathrm{Mnn} \mathrm{I} 2$ & T $c^{s}$ deletion mutant derived from BJMnl0 & Abdul-Jabbar \& Snyder (1984) \\
\hline
\end{tabular}


David et al. (1982a). To follow the kinetics of formation and further processing of host tRNA fragments during infection, the bands containing them were excised from the gel and counted.

\section{(c) RNA fingerprint analysis}

This was carried out according to Brownlee (1972) and Silberklang et al. (1979).

\section{(d) RNA-DNA hybridization}

DNA of the indicated bacteria was digested to completion with HindIII restriction endonuclease. The DNA fragments were blotted onto nitrocellulose (Southern, 1975) and probed with $\left(5^{\prime}-{ }^{32} \mathrm{P}\right)$-labeled CTr5X-specific tRNA fragment $3^{\prime}$-A. The hybridization was carried out in $0.5 \%(\mathrm{w} / \mathrm{v})$ sodium dodecyl sulfate. $0.02 \% \quad(\mathrm{w} / \mathrm{v})$ bovine serum albumin, $0.02 \% \quad(\mathrm{w} / \mathrm{v})$ polyvinylpyrrolidone, $0.02 \%$ (v/v) Ficoll, $0.01 \%$ (w/v) denatured salmon sperm DNA in $6 \times \mathrm{SSC}$ containing $10^{4}$ to $10^{5}$ ets $\min ^{-1} \mathrm{ml}^{-1}$ of the tRNA fragment (Denhardt, 1966; Maniatis et al., 1982) for approximately $4 \mathrm{~h}$ at $52^{\circ} \mathrm{C}$ ( $\mathrm{SSC}$ is $0.15 \mathrm{M}-\mathrm{NaCl}, 0.015 \mathrm{M}$-trisodium citrate, $\mathrm{pH} 7$ ). The filter was washed in $2 \times \mathrm{SSC}$ at $25^{\circ} \mathrm{C}$ and autoradiographed.

\section{Results}

(a) stp mutants are deficient in the anticodon nuclease

The T4-induced anticodon nuclease was monitored in vivo by following the appearance of host tRNA fragments in infected $E$. coli CTr5X cells. We previously designated these fragments by roman numerals, according to their electrophoretic mobility (David et al., 1982a,b). Here, we rename them $\quad 5^{\prime}-\mathrm{L}(\mathrm{I}), \quad 3^{\prime}-\mathrm{L}$ (IV), $\quad 3^{\prime}$-A (II), $\quad 3^{\prime}$-B (III), $5^{\prime}-\mathrm{B}(\mathrm{V})$ and $5^{\prime}-\mathrm{A}(\mathrm{VI})$, to denote, respectively, the $5^{\prime}$ or $3^{\prime}$ portions of leucine $\mathrm{RNA}_{1}(\mathrm{~L})$ or the major (A) or minor (B) fragment pairs generated by the anticodon nuclease.

Since $s t p^{-}$mutations suppress the effects of $\mathrm{pnk}^{-}$ and $\mathrm{rli}^{-}$mutations in E. coli CTr5X, it seemed possible that $s t p$ encodes the nuclease responsible for the anticodon cleavages. Accordingly, stp mutants were assayed for their ability to induce them. Among the strains investigated were mutants with deletions in st $p$ and the nearby $a c$ gene (Depew et al., 1975). Figure 1 shows a host tRNA cleavage pattern obtained during infection of $E$. coli CTr5X with $s a \Delta 3$. a strain with a deletion of $230( \pm 50)$ base-pairs that spans $s t p$ and $a c$ only (Depew et al., 1975). This strain and other sa deletion mutants did not induce the cleavage of the CTr5X-specific tRNAs. This by itself does not prove that the $s t p$ gene is responsible for the anticodon cleavages, since more than one gene is deleted in $s a \Delta 3$. Since spontaneous apparent revertants of $\mathrm{pnk}^{-}$and $\mathrm{rli}^{-}$mutants usually have point mutations in stp, we examined such mutants for their ability to induce the anticodon nuclease activity. We have isolated them from the following parent strains: pseT $\Delta 1, p s e T 2$ and rli-13 (see Table 1). The seven revertants of $p s e T \Delta l$ that were

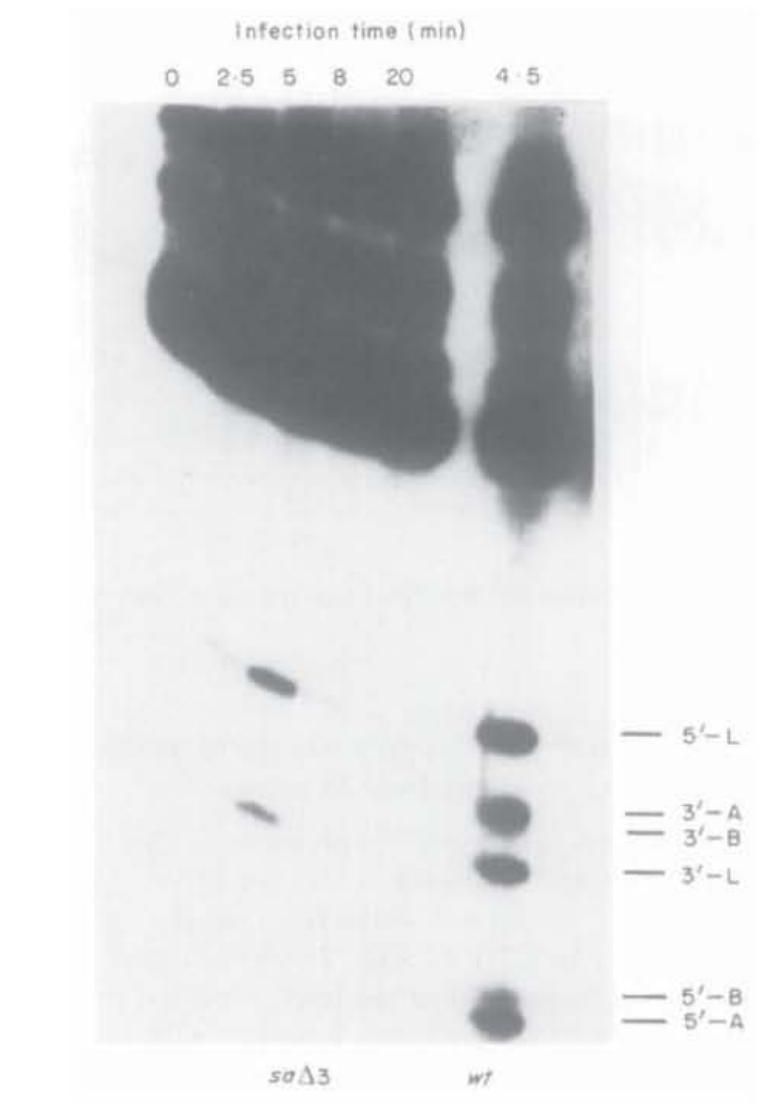

Figure 1. Host tRNA cleavage patterns during infection of $E$. coli CTr5X with a T4 stp deletion mutant. Host tRNA cleavage during infection of $E$. coli CTr5X with the T4 strain $s a \Delta 3$ was followed as described in Materials and Methods. A time-point from $w t$ infection was included to mark the positions of the anticodon nuclease reaction products. $5^{\prime}-\mathrm{L}$ and $3^{\prime}-\mathrm{L}$ denote leucine tRNA $_{1}$ fragments, while $5^{\prime}-\mathrm{A}, 3^{\prime}-\mathrm{A}, 5^{\prime}-\mathrm{B}$ and $3^{\prime}-\mathrm{B}$ denote the major (A) and minor (B) tRNA fragment pairs generated by the anticodon nuclease.

examined generated the leucine $t R N A_{1}$ fragments but not the anticodon nuclease reaction products similar to the stp deletion mutants. Also, of ten revertants obtained from the strain $p s e T 2$, two that were designated $p s e T 2 \mathrm{Rb}$ were specifically impaired in the anticodon nuclease, similar to $s a \Delta 3$. When the $\mathrm{Rb}$ revertants were crossed with the pseT2, sa $\Delta 3$ double mutant, no recombinants able to grow on $E$. coli CTr5X were obtained, indicating that the inactivating $\mathrm{Rb}$ mutations were also in $s t p$. Among the rli-13 revertants characterized, one generated and further processed the anticodon nuclease reaction products, similar to wt phage. Apparently, this revertant regained the $\mathrm{Rli}^{+}$ phenotype. The second $r l i-13$ revertant lacked only the anticodon nuclease reaction products, as found with defined $s t p^{-}$mutants. Taken together, these results indicated that $s t p$ determined the expression of the anticodon nuclease. Incidentally, the leucine tRNA $_{1}$ fragments appeared after infection with stp ${ }^{-}$mutant, confirming that this tRNA is cleaved by a different enzyme, distinct from the anticodon nuclease. 


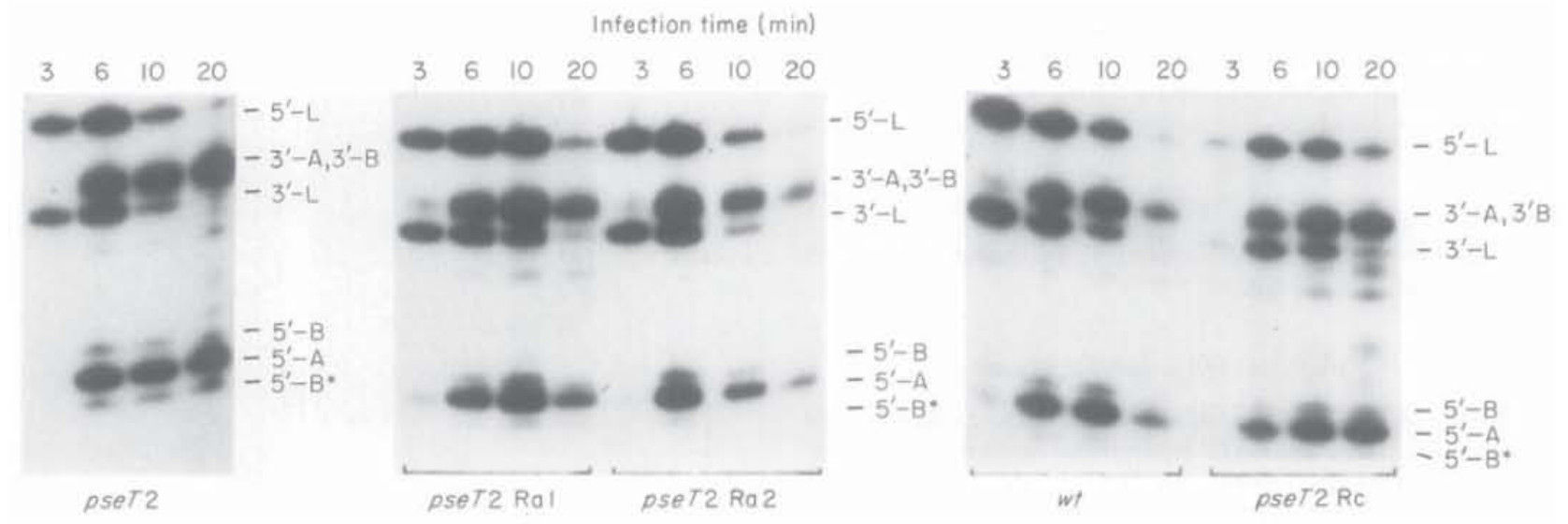

Figure 2. Host tRNA cleavage patterns during infection of $E$. coli (Tr5X with some revertants of the phage strain pseT2.

\section{(b) Other pnk ${ }^{-}$suppressor mutations that are distinct from stp}

There were eight $p s e T 2$ revertants that did not feature the $s t p^{-}$phenotype. i.e. selective loss of the anticodon nuclease activity. Most of these revertants (pseT2 Ra, Fig. 2) yielded and further processed the anticodon nuclease reaction products, similar to wild-type phage. Another wild-type trait in some of these revertants was the lack of the $5^{\prime}-\mathrm{B}^{*}$ derivative $\left(\mathrm{V}^{*}\right)$. This derivative is characteristic of pse $T$ and $r l i$ lesions (David et al., 1982b). Therefore, it is conceivable that the $\mathrm{Ra}$ reversions restored the $\mathrm{Pnk}^{+}$phenotype to varying degrees. One of the eight revertants that did not feature the $s t p^{-}$ phenotype yielded and apparently accumulated the anticodon nuclease reaction products (Fig. 2, pseT'2 Re), similar to the $p s e T 2$ parent strain. The revertant pse $T 2 \mathrm{Rc}$ yielded recombinants that were restricted on $E$. coli CTr5X when crossed with $s a \Delta 3$ phage. Thus, the suppressing mutation in pseT2 Rc seems to reside in a gene other than stp. and is probably too far removed from pse $T$ to be an intracistronic suppressor.

(c) Cotransduction of ('Tr.5X prr function and ability to manifest the anticodon nuclease activity

To determine whether prr is related to the specific manifestation of the anticodon nuclease activity in $E$. coli (Tr5X. we examined $E$. coli BJMni0, a prr-transductant of the permissive recipient strain E. coli B834 (Abdul-Jabbar \& Snyder, 1984) for host tRNA cleavage patterns. Indeed, we found that $E$. coli BJMn10, but not B834, featured a transient appearance of tRNA

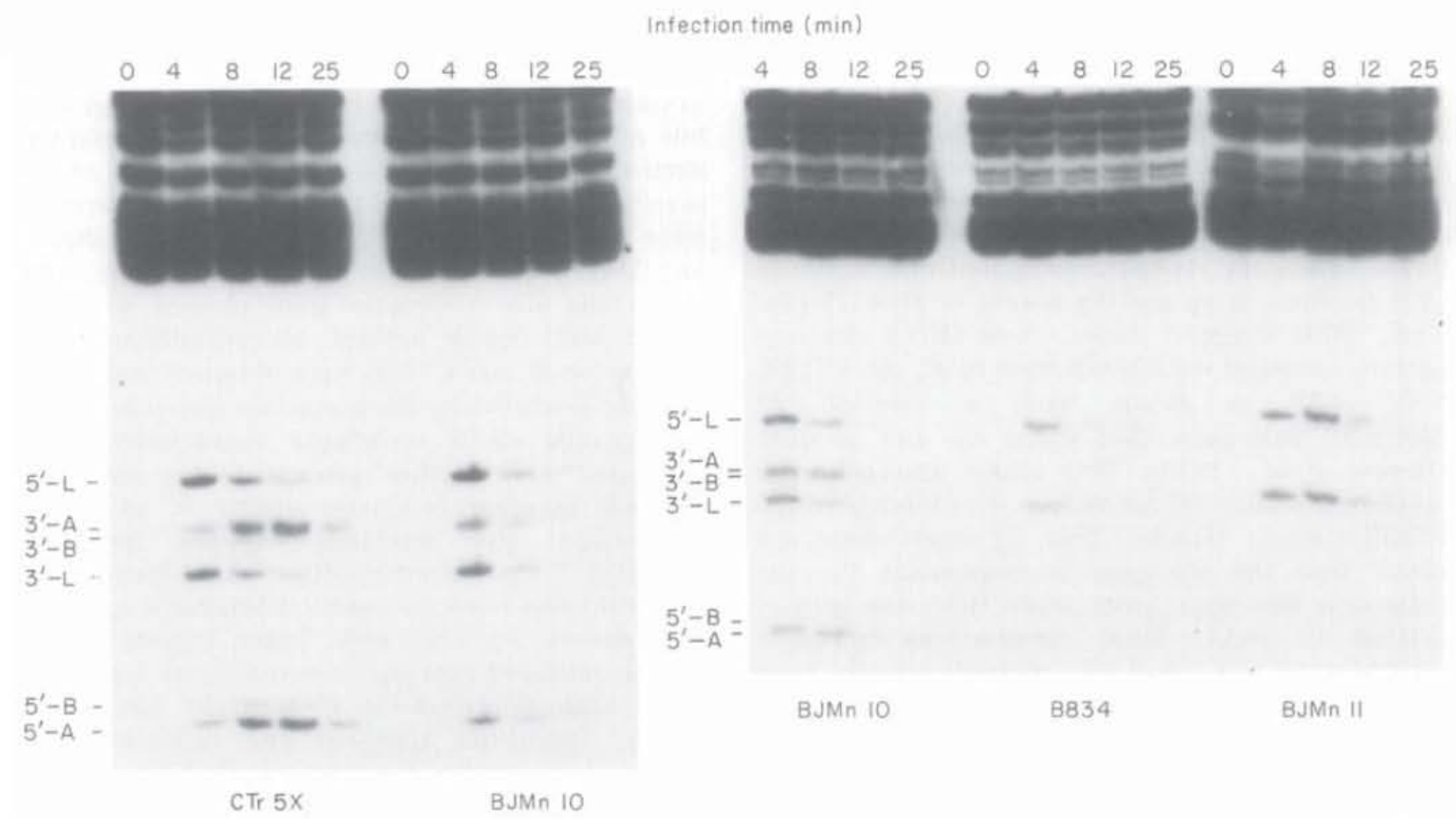

Figure 3. Comparison of host tRNA cleavage patterns of T4-infected E. coli B834, BJMn10, BJMnII and ( $T r 5 X$. 


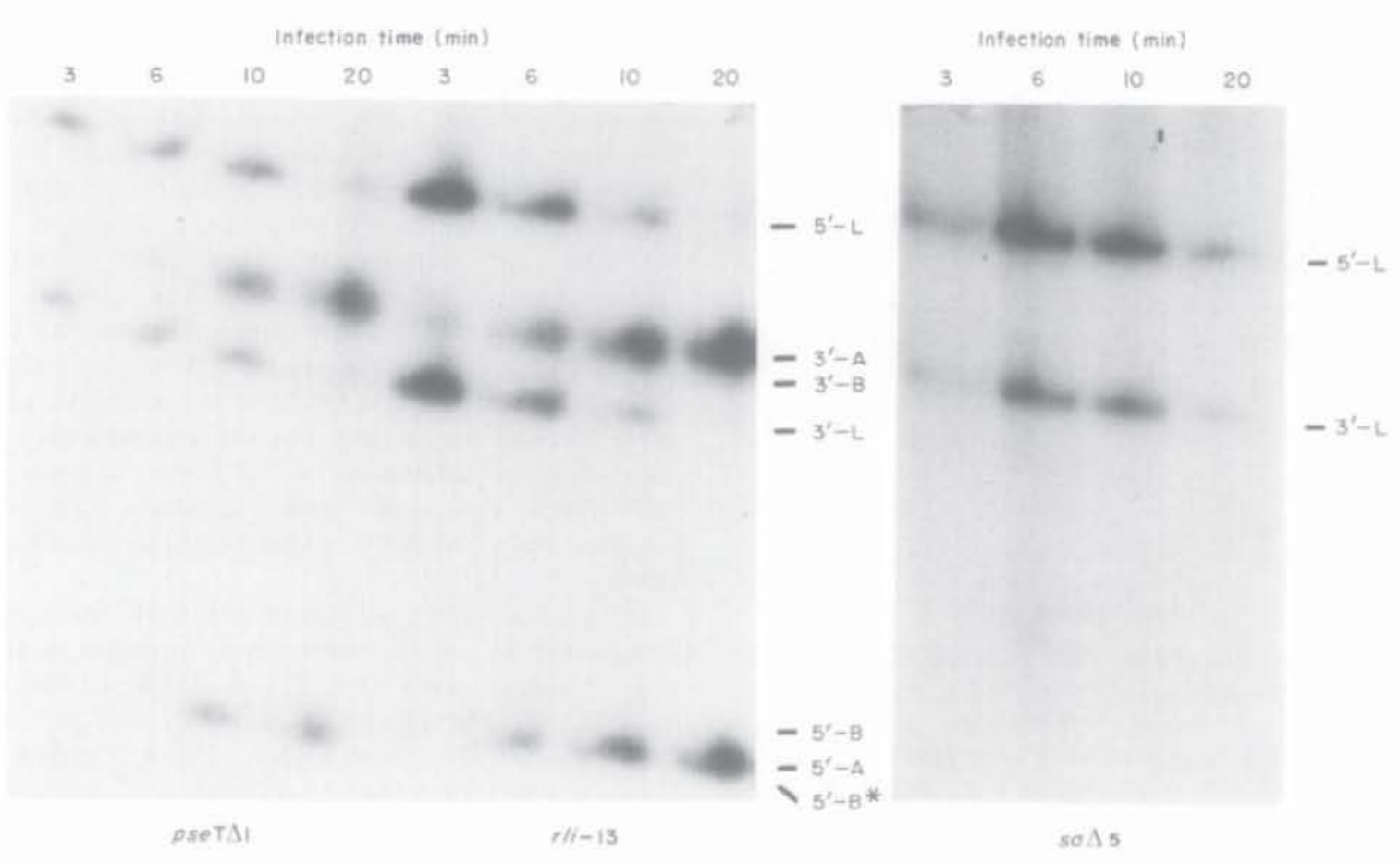

Figure 4. Host tRNA cleavage patterns of E. coli BJMn10 infected with various T4 mutant strains

fragments matching in electrophoretic mobility those specific to $E$. coli CTr5X. That these products were not seen with the permissive recipient $E$. coli B834 (Fig. 3) agrees with results reported for other $\mathrm{pnk}^{-}$permissive strains (David et al., 1982a). Likewise. during infections of $E$. coli BJM10 with pse $\mathrm{T}^{-}$or $\mathrm{rli}^{-}$strains, the matching products accumulated while with st $p^{-}$strains they did not appear (Fig. 4), as found with the corresponding infections of $E$. coli CTr5X (David et al., 1982b; and Fig. 1). Comparisons of RNase $T_{1}$ fingerprints indicated that the BJMn10 tRNA fragments were similar to, if not identical with, the CTr5X counterparts (shown for $5^{\prime}-\mathrm{A}$ in Fig. 5). Thus, the host tRNA cleavage phenotype exhibited by the transductant $\mathrm{BJMn} 10$ was qualitatively similar to that of CTr5X.

Despite this qualitative similarity, the transient
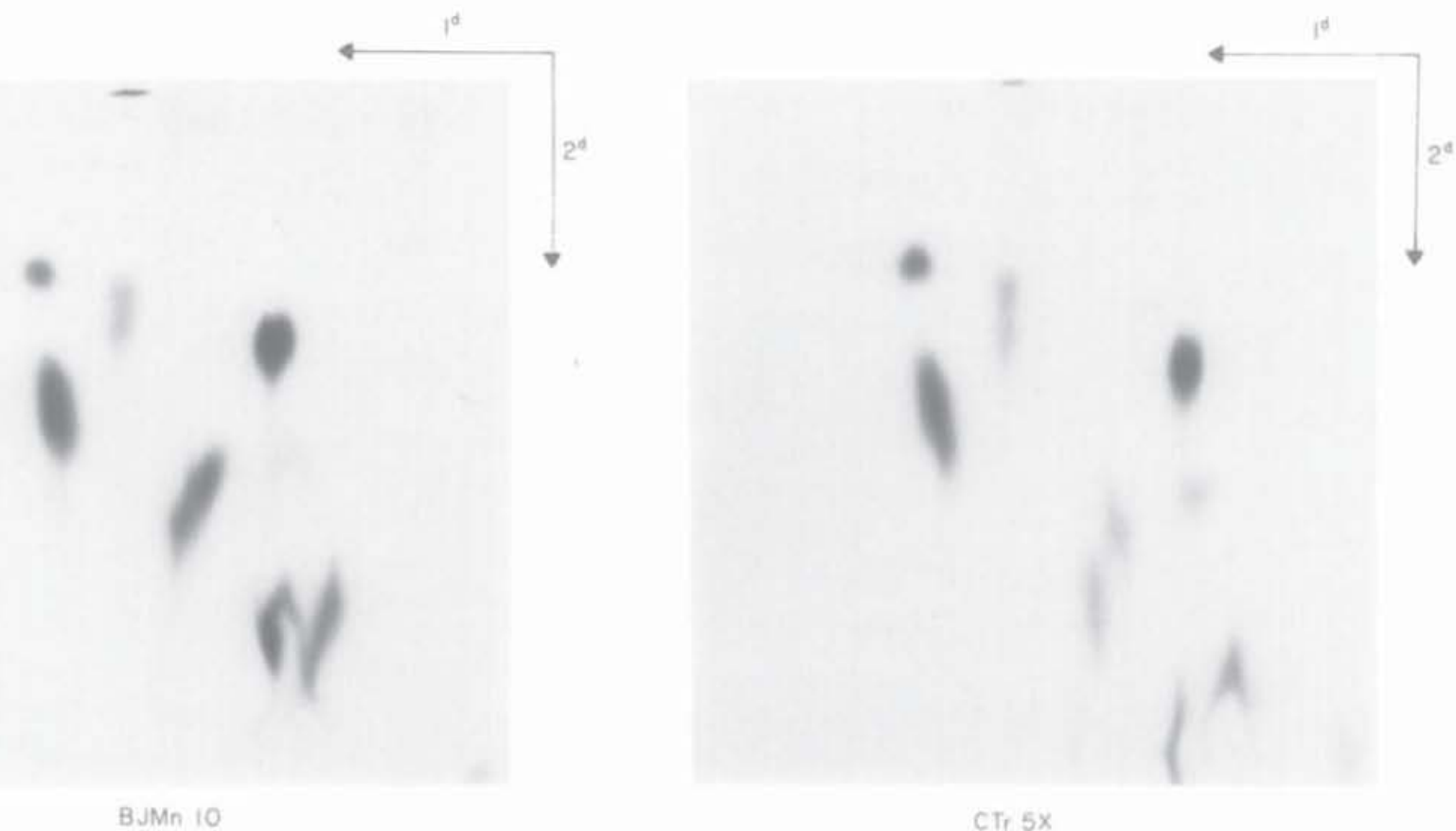

Figure 5. Comparison of RNase $\mathrm{T}_{1}$ fingerprints of the anticodon nuclease product $5^{\prime}$ - $\mathrm{A}$ from $E$. coli CTr5X and B.JMn10. 


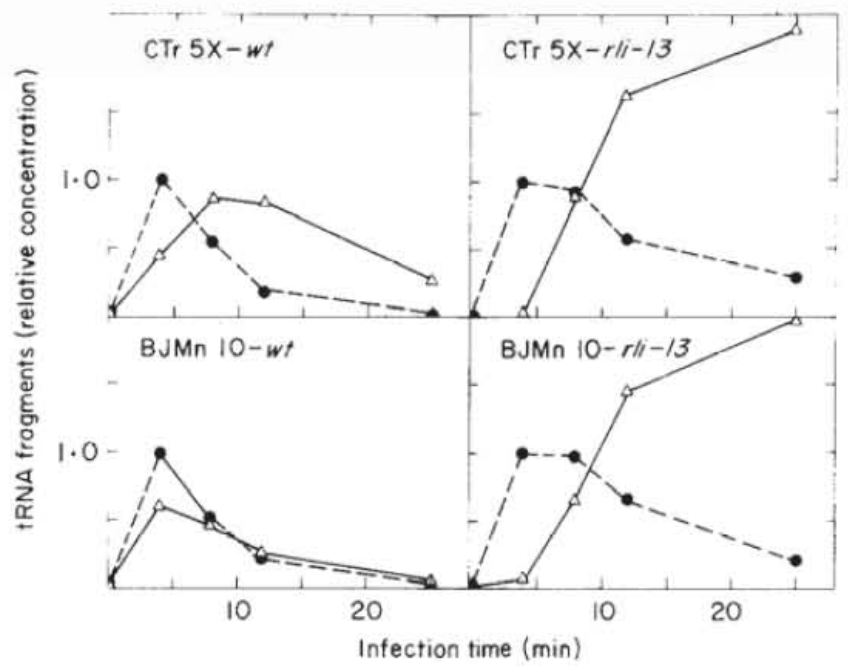

Figure 6. Kinetics of host tRNA cleavage and further processing in T4-infected E. coli CTr5X and BJMn10. The amounts of leucine $\operatorname{tRNA}_{1}(-)$ and CTr5Xspecific $(\triangle)$ tRNA fragments were normalized relative to that of leucine $\mathrm{RNA}_{1}$ fragments at $4 \mathrm{~min}$ infection time.

level of the anticodon nuclease reaction products (relative to that of leucine $\mathrm{tRNA}_{1}$ fragments) during $w t$ infection of $E$. coli BJMnl0 was found to be about twofold lower than in the corresponding CTr5X infection (Fig. 6). In $\mathrm{rli}^{-}$(and probably $p n k^{-}$) infections of BJMn10, the maximal extent of anticodon nuclease reaction products was similar to that seen with $E$. coli CTr5X but was attained at a somewhat slower rate. These data suggested a decreased rate of anticodon loop cleavage but an unaltered rate of further processing of the cleavage products in the prr transductant strain E. coli BJMnl0 and, furthermore, that the vulnerable tRNA levels are similar in the donor and transductant strains. In agreement with these observations, there are slight differences between E. coli BJMn10 and CTr5X in the strength of the prr-mediated restriction. On the transductant, the restriction is alleviated at a lower temperature $\left(37^{\circ} \mathrm{C}\right)$ and some $p n k^{-}$point mutants form small plaques even at $30^{\circ} \mathrm{C}$ (Abdul-Jabbar \& Snyder. 1984).

Other evidence connecting prr with the specific manifestation of the anticodon nuclease activity was obtained with the E.coli BJMnl0 deletion derivative BJMnll, which has lost the prr locus (see Table 1). The host IRNA cleavage pattern of BJMnll resembled that of permissive $E$. coli strains (Fig. 3).

(d) prr does not encode the vulnerable tRNAs

We examined whether the specific manifestation of the anticodon nuclease was due to the encoding of the vulnerable tRNA species by prr. We compared the hybridization patterns of a $\left(5^{\prime}-{ }^{32} \mathrm{P}\right)$. labeled vulnerable tRNA fragment $\left(5^{\prime}-\mathrm{A}\right)$ to
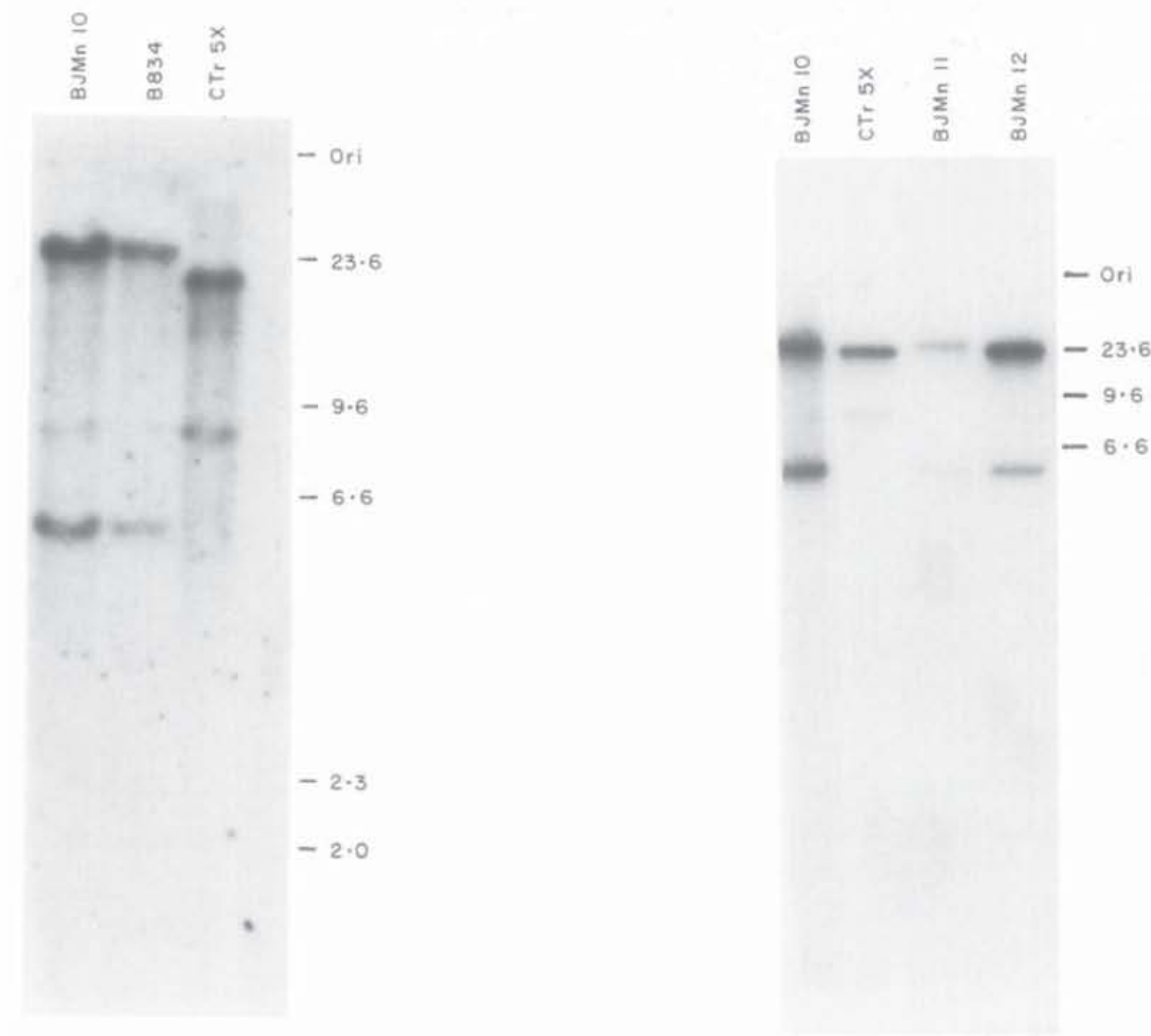

Figure 7. Hybridization of $\left(5^{\prime}-{ }^{32} \mathrm{P}\right)$-labeled CTr5X-specific tRNA fragment $3^{\prime}-\mathrm{A}$ to Southern blots of HindIII restricted DNAs from $p r r^{p}$ or $p r r^{r} E$. coli strains. Sizes ( $\times 10^{-3}$ base-pairs) are indicated. 
Southern blots of restricted genomic DNAs from E. coli B834, BJMn10, BJMn11, BJMn12 and CTr5X. Strikingly, the same HindIII restriction fragments were lit up by the probe in the four B strains, whether prr permissive or prr restrictive (Fig. 7). The identity of E. coli BJMnl0 and BJMnll patterns, despite the large deletion that removes prr from the latter (Green \& Snyder, unpublished results) suggested by itself that the vulnerable tRNA genes exist in both $p r r^{r}$ and $p r r^{p}$ strains, and that prr does not encode the vulnerable tRNA species. The difference observed between E. coli CTr5X and the other strains probably indicates a corresponding difference between the organization of the region in the genome encoding the vulnerable tRNA species in $E$. coli $\mathrm{B}$ and $\mathrm{K}-12$ strains, since the CTr5X pattern resembled that of the permissive K-10 strain (not shown).

\section{Discussion}

(a) stp probably encodes an anticodon nuclease protein

We have shown that the stp gene of $\mathrm{T} 4$, previously defined as an extracistronic suppressor of $\mathrm{pnk}^{-}$and $\mathrm{rli}^{-}$mutations (Depew \& Cozzarelli, 1974; Depew et al., 1975; Sirotkin et al., 1978; Runnels et al., 1982), is required for the anticodon nuclease activity (Fig. 1). st $p$ is transdominant in mixed infections, indicating that it encodes a diffusable product (Depew \& Cozzarelli, 1974), while the anticodon nuclease depends on a translation event set on two to three minutes post-infection (David et al., 1982a), commensurate with the expected time needed by RNA polymerase to travel from early promoters at 164,500 base-pairs to $s t p$ (Gram et al., 1984). Hence, stp is probably a structural gene of the anticodon nuclease or a subunit of it. We have found at least one other extracistronic suppressor that is distinct from stp for at least one pnk mutant. However, it may be unrelated to the anticodon nuclease.

\section{(b) prr determines the specific manifestation of the anticodon nuclease}

We have shown that the presence of the prr locus causes the appearance of the anticodon nuclease reaction products after infection (Figs 3 to 5 ). Regarding the nature of $p r r$, based on the similar hybridization patterns of the vulnerable tRNA fragment to $p r r^{r}$ and $p r r^{p}$ genomes, it appears not to encode the vulnerable tRNAs (Fig. 7). Moreover, a prr-cosmid probe lights up homologous DNA restriction fragments in the restrictive genomes of E. coli CTr5X and BJMnl0 but not in the permissive B834 and BJMnl1 (Green \& AbdulJabbar, unpublished results). Therefore, we consider other possible roles of prr. One is to encode an activity connected with tRNA modification. According to this view, the vulnerable BJMn10 or CTr5X tRNAs may differ from their putative counterparts in the permissive host in a posttranscriptional modification. To examine this possibility we are currently comparing the major vulnerable tRNA species from $E$. coli CTr5X and $\mathrm{BJMn} 10$ with a corresponding B834 species.

A second possible role of $\mathrm{prr}$ is to encode a subunit or factor of the anticodon nuelease. This view predicts that an anticodon nuclease activity may be found only in infected $p r r^{r}$ cells. The reduced rate of anticodon cleavages in E. coli BJMn10, compared to CTr5X (Fig. 6), can be fitted in each of the above two schemes by assuming in the first case a weaker reactivity of the vulnerable BJMnl0 tRNA due to a different degree of base modification, or a lower level of the anticodon nuclease host component in the transductant, in the second.

The third possibility is that prr encodes an inhibitor of a putative host ligation pathway. Accordingly, the vulnerable tRNA species are also cleaved in $p r r^{\mathrm{p}}$ strains but cannot be detected because they are rapidly processed. By contrast, in prr $^{\mathrm{r}}$ strains the host pathway is inhibited and the phage depends on its $p n k$ and $r l i$ products for repair of the vulnerable tRNAs. Hence, the vulnerable tRNA fragments may appear transiently before sufficient levels of these enzymes have accumulated. if the $s t p$ product appears first.

(c) Functional relation of anticodon nuclease, polynucleotide kinase and RNA ligase and possible mechanism of prr restriction and its suppression

The suppression of $\mathrm{pnk}^{-}$or $\mathrm{rli}^{-}$mutations in E. coli CTr5X by a second mutation that inactivates the anticodon nuclease reinforces previous conclusions that the anticodon nuclease reaction products must be further processed in this host, presumably through phosphoryl group rearrangement followed by religation (David et al., $1982 a, b)$. We have shown elsewhere that at least one E. coli CTr5X tRNA species is cleaved and religated during $\mathrm{T} 4$ infection without a detectable net change (Kaufmann \& Amitsur. 1985).

For the sake of simplicity, we assume that the cleavage and religation products that we have monitored, and not others that might have escaped detection, are responsible for the phage restriction phenomenon. We attribute prr restriction to the cleavage of the vulnerable tRNA species which, in turn, may cause the previously observed lesions in T4 DNA replication and late gene expression (Depew \& Cozzarelli, 1974; Sirotkin et al., 1978; Runnels et al., 1982). It is noteworthy that the inhibition of late protein synthesis is indiscriminate, i.e. both true late gene products and early gene products whose syntheses are not turned off normally even late in infection are affected (Runnels et al., 1982), lending support to the proposal of a primary prr effect at the level of translation. However, prr has been shown to restrict mutants in mot (D. Hall, personal communication), a T4 gene that modulates middle 
mode transcription (see Brody et al., 1983). Therefore, interference with a transcriptional process cannot be excluded.

We propose two general hypotheses to explain the relation between the cleavage of the vulnerable tRNAs and inhibition of T4 development. According to one, the anticodon nuclease reaction products themselves are inhibitory to a phage process, perhaps by acting as tRNA analogs. According to the second, damage is caused by depletion of one or more vulnerable tRNA species. Although we cannot disprove either hypothesis, we can try to evaluate them by considering relevant data.

The inhibition of late protein synthesis and prr restriction are alleviated at $42^{\circ} \mathrm{C}$ (Runnels et al. 1982 ) but the anticodon nuclease reaction products still accumulate at this temperature (unpublished results). It is possible that the cleaved tRNAs are partially melted at the elevated temperature, with consequent reduction of their inhibitory potential. Alternatively, the lack of the depleted tRNA may be compensated by another pathway that functions at the higher temperature.

Another problem posed by these models is that the anticodon nuclease reaction products persist in wt infection for a considerable time, during which they are "tolerated". This problem is accentuated by the existence of a pse T2 revertant (Fig. 2, pseT.2 Re) that still accumulates the anticodon nuclease reaction products. Thus, on the one hand, to exer1 an inhibitory effect, the products must reach a high threshold level at a critical time point in infection. On the other hand, the depletion model requires that the false revertant with the undetectable anticodon nuclease impairment allows sufficient levels of the intact vulnerable tRNA, or bypasses the need for it.

The existence of the cleavage repair pathway raises a question about the advantage provided by phage genes whose products interfere with its own development. Clearly, indicator host strains on which stp is essential should be sought in a quest for possible advantages of the anticodon nuclease or other functions that the $s t p$ product may assume. Additional roles of the anticodon nuclease, polynucleotide kinase and RNA ligase in host tRNA inactivation, conversion into new species or replacement by phage-encoded tRNAs do not seem to apply in E. coli CTr5X, since inactivation of the anticodon nuclease restores growth on the $\mathrm{prr}^{\mathrm{r}}$ host. Nonetheless, such roles may be relevant in other hosts.

This work was supported by U.S. National Institutes of Health grants (GM34124 to G.K. and GM2800I to L.S.).

\section{References}

Abdul-Jabbar. M. \& Snyder. L. (1984). , J. Virol. 51, 522529 .
Becker. A. \& Hurwitz. I. (1967). . B. Biol. (Tem. 242.936 950 .

Brody, E.. Rabussay. D. \& Hall, I). H. (1983). In Bacteriophage T4 (Mathews. ( . K.. Kutter. E. M.. Mosig. (. \& Berget, P. B.. eds). pp. 174-183. ASM Publications, Washington, D.C

Brownlee, G. (3. (1972). In Laboratory Techniques in Biochemistry and Molecular Biology (Work, T. S. \& Work, E.. eds), vol. 2, pp. 1-265. North Holland. Amsterdam.

Cameron. V. \& Uhlenbeck, O. (. (1977). Biochemistry, 16. $5120-5126$.

David. M.. Vekstein. R. \& Kaufmann. (: (1979). Prox. Nat. Acad. Sci.. U.S.A. 76, 5430-5434.

David, M., Borasio, G. D. \& Kaufmann (: (1982a) Proc. Nat. Acad. Sci., I'S.A. 79, 7097-7101.

David, M.. Borasio, (A. D. \& Kaufmann. (i. (1982b). Virology, 123, 480-483.

Denhardt, D. T. (1966). Biochem. Biophys, Res. Commun. 23, 641-646.

Depew, R. E. \& (ozzarelli, N, R, (1974), \&. lirol 13 888897

Depew. P. F. Snopek, T. J. \& Cozzarelli. X. R. (1975) Virology, 64, 144-152.

Gram, H.. Liebig, H. D.. Hack, A.. Niggemann. E. \& Ruger. W. (1984). Mol. Gen. Genet. 194, 232-240.

Higgins. P. \& Cozzarelli. N. R. (1979). Methods Enzymol. $68,50-71$.

Kano-Sueoka, T. \& Sueoka, N. (1968), J. Mol. Biol. 37. $475-491$.

Kaufmann, (i. \& Amitsur. M. (1985). Nucl. Acids Res 13. $4333-4342$.

Kaufmann, (A. \& Kallenbach. N. R. (1975). Nature (London). 254, 452454 .

Kleppe, K. \& Lillehaug, J. R. (1977), Adran. Enzymol. $68,245-27 \bar{j}$

Maniatis, T., Fritsch. E. F. \& Sambrook. I. (1982). Molecular Cloming, Cold Spring Harbor Laboratory Press. Cold Spring Harbor. N.Y

Richardson. ('. C. (1965). Proc. Nat. Acad. Nci.. L.S.A. 54. $158-165$.

Runnels, J. M., Soltis, D.. Hey. T. \& Snyder. L. (1982). J. Mol. Biol. 154. 273-286.

Silber, R. Malathi, V. (․ \& Hurwitz. J. (1972). Pror. Nat. Acad. Sci.. U.S.A. 69, 3009-3013.

Silberklang. M., Gillum, A. M. \& RajBhandary, L'. T (1979). Methods Enzymol. 59. 58-109.

Sirotkin. K.. Cooley. W. Runnels, I. M. \& Snyder, L. (1978) . . Mol. Biol. 123. 221-233.

Snopek. T. J.. Wood. W. B.. Conley. M. P.. (hen. P. \& Cozzarelli. N. R. (1977). Proc. Nat. Acad. Sci.. It.S.A. 74. $335 \tilde{5}-3359$.

Snyder, L. (1983). In Bacteriophage T4 (Mathews, ('. K.. Kutter. E. M., Mosig. G. \& Berget. P. B., eds). pp. 351-355. ASM Publications, Washington. D.C.

Snyder, L.. Gold. L. \& Kutter, B. (1976). Proc. Nat. Acad. Sci.. I.S.A. 73, 3098-3102.

Southern, F. . I. (1975). J. Mol. Biol. 98, 503-517

IThlenbeck, $O \& \&$ (iumport, R I (1982). In The Enzymes (Boyer. P., ed.), 3rd edit.. pp. 31-58. Academic Press, New York.

Wood. W. B. (1966). J. Biol. Chem. 253, $2437-2445$.

Wood, W. B. \& Henninger. M. (1969). . . Mol. Biol. 39. 603-618.

Yudelevich. A. (1971). I. Mol. Biol. 60, 21-29. 